\title{
Resurfacing Female Identity via Language in Adrienne Rich's Diving into the Wreck
}

Mohamad Fleih Hassan

UPM, mohamedfleih@yahoo.com

\author{
Dr. Rosli bin Talif
}

UPM, rt6272@gmail.com

\section{Dr. Hardev Kaur}

UPM, hardevkaur@upm.edu.my

\author{
Doi:10.5901/mjss.2015.v6n6s2p245
}

\section{Abstract}

\begin{abstract}
Adrienne Rich (1929-2012) is a representative poet of American women's poetry. The subject of female identity is a dominant theme of American feminist poetry and Rich plays the leading role in search of this identity. Rich couldn't find herself as a woman writer in the language she uses because it is a symbolic masculine language; therefore she introduced a new possibility of actualizing the female identity through the restructuring of this language. Thus, the objective of the study is to trace the semiotic aspect of language in Rich's Diving into the Wreck to see the role of this Semiotic aspect in subverting the fixedmeanings of the symbolic language, which in turn leads to the resurface of the buried female voices within this language. It explores too Rich's poetic discourse concerning the restructuring of female identity by the means of language. The study employs Kristeva's concept of The Semiotic and The Symbolic in analyzing Rich's Diving into the Wreck (1973) to regain the feminine elements within the patriarchal language through the signifying process. Since Kristeva thinks that language can be the means for the subject to gain identity, so the application of her concept of The Semiotic and The Symbolic is relevant here. Rich utilizes the image of 'Diving' into history to show the need for a language that resurfaces the long-silenced voices of women in order to help them prove their own female identities far of the oppressive patriarchal discourses. The study concludes that Rich in 'Diving into the Wreck' exhibits a transformative understanding of the status of women reclining on the restructuring and resurfacing of female identity through the way of using a unified unbiased language.
\end{abstract}

Keywords: female identity; semiotic; symbolic; language; signifying process; patriarchal discourse.

\section{Introduction}

Adrienne Rich (1929-2012) is one of the significant feminist American poets in the postmodern era. In her many journals and essays, Rich shows a constant search for the discovery and recognition of the female voice. Her books of poetry display a progression of thought about womanhood. She has written many prose writings that enriched the feminist schools of thought. She is an early advocate of the urgent needs to do social and political changes that express the real needs and aims of women's movement. Some of her writings become indispensable poetic statements for the feminist theory.

Rich widens the scope of poetic language away from the numerous contemporary definitions of language as signs to be manipulated. Rich believes in the significance of language in changing the conditions of women and the female principle. "Language that is returned to the female principle will provide the basis for social change; and, because it has played an important part in socializing men and women, it can also be used to redefine and to change existing reality." (Farwell, 1977, p. 200)

Katherine Soules conducted a comparative study entitled Revitalization of Female History: An Analysis of Adrienne Rich's Diving into the Wreck and The Dream of Common Language (2011). She focused in this study on the progression of thought in Rich's career which started with the desire for androgyny. This desire can be achieved through reviving the female history that was buried by the patriarchal thought. She compared Rich's thesis of androgyny in Diving into the Wreck to her new thesis delivered in The Dream of Common Language, which entails the urgent need to the rewriting of female history in the light of the new feminist perspectives. 
Soules said that Rich gave up androgyny because "the patriarchal structure of the twentieth century, with which Rich was contemporary, hindered achievement of androgyny because of the elevation of the masculine viewpoint above the feminine" (2011, p. 1242). Therefore, Rich resorted to a completely different approach, which is the rewriting of female history by two means: the abolishing of the traditional role of women and the recording of history of the successful women. Soules concluded that Rich introduced a new vision of common language that breaks away of the patriarchal thought, but her analysis of Rich's theses relies only on the theories and poetics of Rich with no reference to any major feminist theorist.

Erkan approached Rich's Diving into the Wreck, but through an Ecofeminist perspective. She showed in her study entitled, An Ecofeminist Approach to Adrienne Rich's Poem 'Diving into the Wreck' (2012) that Adrienne Rich's poetic vision proved the role played by the cultural and patriarchal ideology in the marginalization and subjugation of both the human and non-human subjectivities simultaneously. She discussed the interrelationship and interrelatedness among each of the human subjectivity, cultural discourse, and nature. Patriarchy always associated women with nature to show her vulnerability and weakness; as such, this time the persona in "Diving into the Wreck" dives into her own nature to explore herself and to express her feminine identity. (ERKAN, 2012, p. 240)

Rich raises her voice calling women to think deeply of the results of following a female tradition that writes from a gendered subjectivity. She describes the urgent need to a poetics of revision, saying that the act of re-vision is to look back, to see with fresh eyes, and to access an old text from a new critical direction. "Rich's poetry insists upon bodily presence, an eroticized, corporeal self that speaks of its desires in ways that we can strongly identify as deriving from the Romantic bodily self.... One of the functions of speaking through and for a marginalized historical woman is to enter her subjectivity to release her hitherto silenced voice" (Roberts, 2008, pp. 94-95). The present study approaches Rich's thesis of the common language through applying Kristeva's concept of the Semiotic. It aims to regain the semiotic maternal elements within the symbolic paternal language in order to achieve Rich's commonality of language.

\section{Kristeva's the Signifying Process}

Kristeva's The Semiotic and the Symbolic (1974) is relevant here to the study of Rich's Diving into the Wreck because both Kristeva and Rich are related to the issue of identity construction through language. Kristeva mixes the theory of language with her theory of subjectivity for she thinks that the speaking being uses language and is constituted by language. She considers language as a dynamic signifying process, unlike the Structuralists who look to language as a static entity. By the term Signifying Process, Kristeva means the various ways of expressing the bodily drives and energy through the use of language and how this process of signification constitutes the subjectivity of the speaking being (McAfee, 2004, p. 14). Therefore, the study of language is inseparable from the study of the speaking subject.

Kristeva says that there are two modes of signification for the speaking subject to constitute language: the Symbolic and the Semiotic. She defines the Semiotic as the maternal space of language and the way of expressing the impulses and drives of the body through language. These impulses and drives are unconscious and reflected in the character's sound, rhythmical sentences and even in the kind of imagery used to convey the feelings and desires by language. The Semiotic lacks structure and meaning and associated with the feminine, and represents the undifferentiated state of the pre-Mirror Stage infant. On the other hand, the Symbolic is the rule-governed patriarchal language. It is reflected in the grammatical and syntactic structures that subject to the patriarchal logic. The semiotic and the symbolic modes of signifying language look contradictory but every mode of signification completes the other in language. Therefore, the signifying system produced by the speaking subject cannot be either Semiotic or Symbolic, but this process is indebted to both of these modalities of signification. (Moi, 1986, pp. 92-93)

Kristeva admits the urgent necessity for the Symbolic to have a logical conscious language, but in order not to make it a biased patriarchal language; it must be continuously renewed through tracing the heterogeneous energy of the unconscious represented by the Semiotic's play of impulses and drives that stands for the residue of the mirror stage. According to Kristeva, these drives appear as a pulsational pressure inside the language itself and are reflected in the speaker's rhythm, tone, imagery, in addition to the contradictory and meaningless utterances, absence and silence. (Petrović, 1997, p. 4)

Lacan's concept of the Symbolic entails the burial of the Semiotic if the child wants to get an access into his own subjectivity. The child should give up his first identification and attachment with his mother in order to construct an identity that copes with the patriarchal model, which in turn favors the masculine over the feminine. Kristeva introduces the concept of the Semiotic stating that it has the power of subversion. The semiotic subverts the Symbolic's mastering over language, giving new spaces and voices to emerge. She says that the semiotic is a modality of the signifying process with an eye to the subject posited; but this subject is posited as absent by the symbolic. (Kristeva, 1984, p. 41) 
Kristeva says that the Semiotic is never ending when the child gets into the Symbolic world, but it still persists within the periphery of consciousness, deconstructing the binary between the masculine and the feminine through emphasizing the interaction between the Semiotic and the Symbolic as the two modalities needed for the signifying process. These two modalities are completing each other within the process of signification that constitutes language, which in turn constitutes one's identity. Kristeva's the Subject in Process is indebted to these two modalities for signification. (Moi, 1986, pp. 92-93)

For Kristeva, the function of the Semiotic is to deconstruct the social fixed meanings of language and its abstract truths because the patriarchal ideology of the world relies on the binary thought system. The Western thought is based on the dichotomies between culture and nature, mind and emotion, conscious and subconscious, the semiotic and the symbolic ...etc. Kristeva looks to such dichotomies in a different way. She says that the semiotic unconscious drives are continuously discharged into the symbolic sign system of the masculine language. Kristeva rejected the binary thinking of the Western society and showed the intertwining of these two dichotomies. Kristeva's point is "the symbolic mode of signification is meaningful because of the way the semiotic energizes it" (McAfee, 2004, p. 18). Modern literature has the power of shocking the reader's consciousness, and forces him to question the validity of these fixed meanings and signs. It demolishes all the bases of the patriarchal thought, which suppress females. Language, as Kristeva thinks, is a vital element in the empowerment of women and their articulation of counter-representations. Male and female writers have recognized that speaking in the tongue of the dominant and powerful has the merit of being subversive and a successful strategy of survival (Gillis, Howie, \& Munford, 2007, p. 80)

\title{
3. Poetics of Adrienne Rich
}

Rich wrote her poems in the early period of her life in order to attract the attention of a particular man for her poetry was influenced by the imitation of white male poets. She wrote her early poems using the language of the male, thus these poems did not really express Rich's female attitudes because this kind of male language didn't reflect the female principle. She wanted to reconsider language that it be able to violate the conventions of poetic writing. She focused on the concept of re-visioning the traditions saying that "Re-vision-the act of looking back, of seeing with fresh eyes, of entering an old text from a new critical direction-is for women more than a chapter in cultural history: it is an act of survival" (Rich, 1972, p. 18). She felt herself incapable of writing poems with pre-planned materials. She said in her Poetry and Experience:

\begin{abstract}
the poem itself engenders new sensations, new awareness in me as it progresses. Without for one moment turning my back on conscious choice and selection, I have been increasingly willing to let the unconscious offer its materials, to listen to more than the one voice of a single idea. Perhaps a simple way of putting it would be to say that instead of poems about experiences I am getting poems that are experiences, that contribute to my knowledge and my emotional life even while they reflect and assimilate it. (Gelpi \& Gelpi, 1993, p. 165)
\end{abstract}

Rich "describes the long process of integrating the two as a political coming-to-consciousness, a moving beyond the conceptual barriers that separated her personal struggles as a young wife and mother from aesthetic and political concerns" (Forbes \& Forbes, 2009, p. 16). She transformed her focus from the public to the personal believing that the political is the personal. Rich's publication of Snapshots of a Daughter-in-Law (1963) and Diving into the Wreck (1973) marked a turning point in her career since she started recovering the buried voice of women through using appropriate tools of language to re-establish the female identity.

Rich's Diving into the Wreck (1973) asserts the need to reinvent the cultural standards in feminist terms and focuses on the necessity for women to re-establish themselves. No male writer has written primarily or even largely for women when he chooses his materials or his language; but every woman writer has written for men even when she is supposed to be addressing women. If women give up being haunted by convention and by internalized fears of expressing themselves, then it will be an extraordinary step for female writers and readers. (Bomarito \& Hunter, 2005, pp. 332-333)

Adrienne Rich's Diving into the Wreck is a story of a diver who carries the burden of having an identity that is not hers. She endeavors to discover the damage that is done to females throughout history by the patriarchal-biased societies. The diver dives into the bottom of the ocean, investigating the wreck to come back with a different story of female history that enhances a new unified identity. She introduces herself as diving into the ocean to explore the wreck of a sunken ship. The wreck stands for the neglected inner lives of women, or perhaps to the deformed civilization ruined by false thought about gender and gender roles. The diver wishes to discard false thought through rewriting history with a 
language that does not bury the voice of women for the sake of proving the power of masculine discourse.

This paper explores the semiotic aspect of language such as sound devices, imagery, rhythm and tone and their role in subverting the meanings dictated by the symbolic aspect of language upon the texts. By doing so, it creates a new space for the female principle to be circulated within the masculine language that will turn into a common language helping women restructuring their own identities without being abused or oppressed by the masculine language.

\section{The Semiotic Elements in Rich's Diving into the Wreck}

\subsection{Metaphor, Simile and Color Imagery}

The persona in Rich's Diving into the Wreck dives deep in the water, which is black and dark. This diving symbolizes that the journey into the bottoms is fearful. The whole poem is built upon the image of diving into the bottoms of unconsciousness to resurrect the female voice and experience. The image of the sea in this poem is a female image (Annas, 1982, p. 18).

Therefore, Rich exploits the image of diving into the bottoms of the sea because she wants to get the attention to the buried treasures. She metaphorizes the burial of these treasures to the burial of the female voices and the burial of the Semiotic Chora within the masculine-dominated symbolic language. Metaphor is a figure of thought and of speech that makes us see one thing as another. It is viewed as 'a rhetorical or poetic departure from ordinary usage, in that it permeates all language and affects the ways we perceive and conceive the world.'(Abrams \& Harpham, 2011, p. 190) She suggests that it is urgently needed to rebirth the Semiotic aspect of language in line with the Symbolic one in case women want to avoid oppression and subjugation.

The diving image is very suggestive in the sense that it entails the diving into the periphery of awareness to recall the Semiotic (the maternal) into the Symbolic (paternal) and thus creating a kind of language that structures both the male and female identities with no reliance on the prejudiced patriarchal thought. Rich helps the reader to be aware that the diver's journey is not an individual journey of self-discovery, but a journey to understand the universality of humanity. The metaphoric use of diving in Rich's poem makes it easily accessed by readers.

Water in this poem provides a medium of reality. The poet uses this reference to water to show how the real, the imaginary and the symbolic can intertwine, and how the imaginary and the symbolic identification fail in the codification of the complexity of reality. The symbolic and imaginary language cannot match up with reality; so that the diver felt alienated from herself because of the symbolic narrative of her 'book of myths.'

The diver searches more liberating forces than the search for the binary thought system of the male/female genders. The diver seeks 'the wreck and not the story of the wreck/the thing itself and not the myth'. The diver is not satisfied with the current story of the female history narrated by masculine writers. She aims to rediscover and rewrite the female history by feminine explorers:

Beyond the difficulties of structuring truth lie the issue of power and sustainability, and how they function in determining gender identities. The diver begins by asserting her independence from the imposed model of gender. Then, by crossing the threshold between air and water-man and woman-she discovers a forgotten history and finds a new integrated-self waiting for her. Rich seems to replace contorted gender roles with a freer paradigm of androgyny. (Hay, p. 2)

The diver rejects to be guided by the symbolic modes and signifiers 'book of myths' in her journey because they are built on exclusion and absence of the other sex. Instead, she wants to be guided by the signifiers of the semiotic maternal world in addition to the symbolic ones, in which both of these modalities are needed for signification. She refuses the masculine story told to her about female history, and decides to start a new journey of rediscovery beginning with the first maternal story that lies under the surface.

Woman within the discourse of patriarchy is associated with nature while man is associated with culture. The entailment of this association is man's liability to thought and women's liability to emotion. This kind of association signifies that man fits logical thinking while woman does not, and that man is qualified to guide while woman is not. This symbolic association pushes Rich to exploit the image of the sea to show a semiotic reference to matriarchy by diving deep into the bottoms of women's unconsciousness in order to resurface their buried voices.

Rich suffered for a very long period of time the conflict between expressing herself and the imitation of the avantgarde male writers. She felt the waning of her creative powers because she talked only about public and universal issues, which are definitely not feminine. At last, Rich got the gut to descend into the wreck of the unconscious submerged 
beneath the social institutions of marriage and motherhood. She utilized the image of diving in this poem to explore her own interior world of darkness. She discovered a landscape of pain, and anger, which forced her to take the diving step in order to resurface these long-forgotten treasures. Such a journey into the unknown inner reveals certain potentials and powers, reflective not only of personal transformation but also of the capacity of women to change their world socially and politically. (Keith, 2012, p. 103) 'First having read the book of myth' represents the historic view of women and their roles in a male society. Rich tries to change this historic perspective by exploiting the diving image as a quest for discovery as she goes in a journey to look for the truth and to rewrite it with an appropriate language.

She used an important metaphor when she 'loaded the camera' which shows her need to be able to capture the truth in a form that she can use as proof of the truths she will discover later. She used the verb 'load' as if she is loading a gun that will be used later. In the depths of the sea, she will know the truth behind the murder of the female voice throughout history; therefore she is loading her camera to use this weapon against the causes of the female oppression and subjugation. Again the image of checking the edge of the knife whether it is sharp or not indicates the persona's state of mind. It gives the impression that there are certain threats lie ahead in her journey from the masculine symbolic world 'the conscious' to the semiotic one 'the subconscious' but she is determined to confront these threats in order to fulfill her mission of self-discovery:

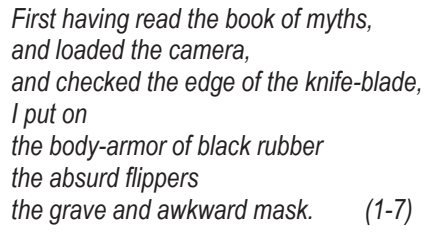

This poem relates a journey from the conscious levels of the mind to the deeper unconscious levels which are forgotten, repressed, or distorted by self and others. The water into which the speaker dives stands for the deeper levels of the mind. The speaker wants to explore the crushed, buried aspects of the mind and heart. She stands for all women who have been forced to suppress their deepest desires, longings, and ambitions because they are using symbolicgoverned language. The wreck of ship found at the bottom stands for the psyche's parts that have not been consciously recognized. The sunken wreck represents everything that has been forgotten, devalued, and suppressed. The poet seeks the truth about these unrecognized regions, therefore, the knife is used for dissecting what she may find in search of truth and a camera to record what is truly discovered. (Milne, 2009, p. 62)

Simile also has its semiotic aspect in the sense that the persona refuses to dive into the bottoms of the sea like Cousteau and his team whose journey to the bottoms was a symbolic one. They used the symbolic elements such as the map, compass and the book of myths to tell the story of women. Therefore, they were biased in their description of women because it was a masculine point of view telling women of how their characters should be. Their masculineoriented discourse favored men over women leaving women in an inferior position in relation to men's superiority. Unlike them, the persona launches into the bottoms alone with no help of the symbolic elements because she wants to see by herself 'the wreck and not the story of the wreck'.

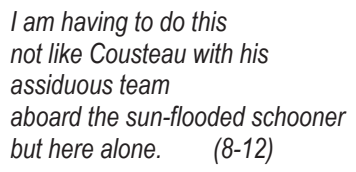

In addition to the metaphors and similes, the persona uses the imagery of colors to express her feeling through variety of colors. Color's signification is important because there is a direct relationship between the perceiver's mood and colors. Colors in the symbolic world are green and blue to indicate that this is the familiar world we live in, but in the semiotic world colors are black and dark to indicate the burial and invisibility of this world. The persona used blue and green to describe the surface but once she dives down, colors turned to be dark and black to show that the world down water is still unseen and forgotten:

First the air is blue and then it is bluer and then green and then black I am blacking out and yet my mask is powerful (34-37) 
The repetition of dark colors throughout the poem reflects the somber and melancholic atmosphere of the underwater world. Her mood had changed and she was blackened herself, but she got the power to go on for her mask 'pumps her blood with power'. Rich used vague descriptions of the diver's first descent to water in order to show how insidious the shift between the world up the surface (symbolic) and the world underwater (semiotic). The diver goes down gradually as the colors change from, 'First the air is blue and then/it is bluer and then green and then black', to show the gradual descent of the diver to the underwater world. The diver wants to get rid of the social limitations and oppressions of the patriarchal world by escaping to the sea bottoms where she can find freedom. Metaphorically, she feels relaxed under the water that she 'breathe differently down here'. The diver descends down to realize the vastness of the ocean; much water and much detail indicate the richness of the hidden world down there.

\title{
4.2 Symbols
}

Another semiotic aspect in this poem is the symbol of ladder. It is significant as a symbol because it helps the diver to go both ways: to stay on the surface (Symbolic) having one-dimensional masculine perspective to life or to go down to the bottoms (Semiotic) exploring what have been long-buried down there, which helps to have a comprehensive masculinefeminine outlook to life. Again, water causes buoyancy, which makes it a little bit difficult to go down to the sea of memories, so the ladder is the link that shifts the diver from the Symbolic into the Semiotic world. Simultaneously, the ladder would help her to head back up from the Semiotic (bottoms of the sea) to the Symbolic (deck). While the ladder is the means of enacting a watery descent that overturns the ascents and conquest stories of males, Rich implies the urgent need for women to distinguish between myth and reality. (Ostriker, 1982, p. 72)

'The ladder is always there, hanging innocently' helps the diver to cross between the world of water and the world of air, which are separated. People think that the ladder hangs there innocently and that it is no more than an ordinary equipment. But once man dives, he will know the importance of the ladder because it takes him to the other world.

I go down.

\author{
My flippers cripple me, \\ I crawl like an insect down the ladder \\ and there is no one \\ to tell me when the ocean \\ will begin. (28-33)
}

Her flippers make her feel uncomfortable and make her crawl like 'an insect' as she uses the ladder to get into the bottoms with difficulty, fully aware that she dives down alone. The journey is a little bit awkward and scary, especially when she realizes that she is alone and that there is no one to guide her. Though she dives by using the ladder, she gives up the ladder in order to explore. She has to do the job alone, 'I have to learn alone to turn my body without force.'

'The book of myths' is also another significant symbol. It symbolizes the male dominance over females for they exploited the falsified narratives of the patriarchal thought written in this book to dictate upon women their inferior identities. The book is not a book of facts but a book full of myths that favor one gender upon the other. It favors the masculine discourse as the one that is fit to survive, and neglects the female discourse accusing it of irrationality, inferiority and invalidity. This unfair book indoctrinates women of what to do and how to behave if they want to be accepted in man's world. Women should follow the instructions of the 'book of myths' and they should live according to the criteria of the masculine world if they want to live or they will face greater marginality and oppression.

Other significant symbols are the book, map, compass and log book. She reads first the story told in the book about wreck and she holds the map in her hand. These linguistic symbols serve as a guide for her in the underwater world. The diver gets an idea about the wreck from the 'book of myths'. But the diver seeks 'the wreck and not the story of the wreck/ the thing itself and not the myth', therefore, when the diver probes the reality of the wreck, she discovers that the tools of navigation used to be useful in the symbolic world are no longer useful in the semiotic world because they are half destroyed and serve one-sided masculine perspective. These tools cause a problem of gender identification. Women write about themselves using man's tools and voice. Simultaneously, they used to follow the formal style of writing which serves the male needs neglecting the female ones. These two problems are connected to language which Rich finds perilous (Gelpi \& Gelpi, 1993, p. 314). These navigational symbols serve no purpose and are completely irrelevant because the wreck isn't going anywhere. Therefore, the diver cannot find their names in the book of myths, 'our names do not appear.'

The speaker's body in Rich's Diving into the Wreck becomes an equipment that she must learn to maneuver 
underwater. Though the poem is about a quest for origins, the speaker focuses her attention on how she must position herself in relation to her search rather that to what she may find. Rich writes:

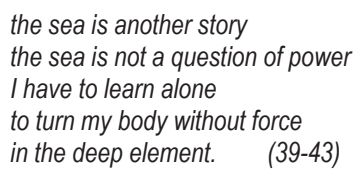

The diver has to cope with the new world because it is different of the world up. Also, she has to find her way of moving in the new world: 'I have to learn alone'. This process of transforming one's life into a new life is not an easy job at all. Watching the scene underwater, she realizes that she must not forget the purpose of her dive. She must depend on herself to explore the wreck.

The poem is written to be a plea for the voices of women to be raised. It refers to the patriarchal nature of American society, in which males determine what is right and what is not for women. Therefore, they left women out of the discourse and tried to shape women's lives as they like, neglecting women's dreams of becoming themselves and for themselves. Rich refers to the book as 'the book of myths', because it becomes a symbol of not documenting the truth but the falsified truth, especially about the lives of women. Hence, the poem is considered as a kind of feminist manifesto, by which women can rewrite the history of their lives and to face the male ignorance and prejudice. (Milne, 2009, p. 63)

\subsection{Alliteration, Repetition, and Tone}

The poem starts with short musical sentences describing the preparations for a journey into the bottom of the sea. The journey will be taken individually, which is clear through the affirmative tone of 'I am having to do this.......but here alone.' There is a sense of determination inside the persona for she started putting on the diving kit without knowing first why she would dive! The determinative aspect of the persona is seen in the use of alliteration of ' $\mathrm{B}$ ' sound in 'the body-armor of black rubber', and in the repetition of the words 'I go down'.

Repetition is part of the semiotic elements of language. In Rich's poem, the repetition of these words 'I go down.', 'I go down.' intensifies the sound effect of the text through its poeticality, and shows the willingness of the speaker to dive down to the bottom of the sea; to the subconscious world with no fear. The following passage gives a drum-like emphasis through the repetition of the word 'down': (Gilbert, 1997, p. 146)

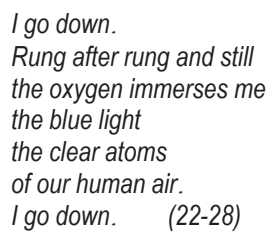

In Rich's poem, the transition from land to sea is gradual, but it is quite clearly a matter of active agency and determination to descend to the unknown bottoms and face the difficulties. Again, the repetition of the word 'then' three times when the persona started diving indicates the speaker's progression in diving to the bottoms and the gradation which was clear in the change of colours from 'blue' into 'green' and then 'black'. Though the persona is blackened out spiritually, she feels powerful for her mask 'pumps my blood with power'.

The events of Rich's poem happen almost entirely in the underwater world, with only a slight reference to the world on surface. The kind of language used in describing the first diving steps underwater indicates that what threatens the diver is the 'human air,' not the water: 'Rung after rung and till / the oxygen immerses me'. She feels that her life in the symbolic patriarchal world is dull and suffocating, whereas the semiotic world underwater helps her to rebirth herself again. The persona is aware of the threats of the underwater world, yet she has the determination to face these threats because she thinks that the knowledge she will acquire there is not simply fatal but potentially redemptive as well. (Gilbert, 1997, p. 148)

The patriarchal structure of the twentieth century hinders achieving the androgynous being due to the preference of the masculine thought over the feminine. The patriarchal thought suppresses the feminine traits and makes it impossible to create balance between the feminine and masculine ones. A woman is expected to remain wholly feminine under 
patriarchal stipulations. Rich tries to empower herself as she has achieved the androgynous ideal. She expresses a need to rediscover the history of women. She goes on in her journey to defy the mythical history. Rich explores the shipwreck of history looking for the real story:

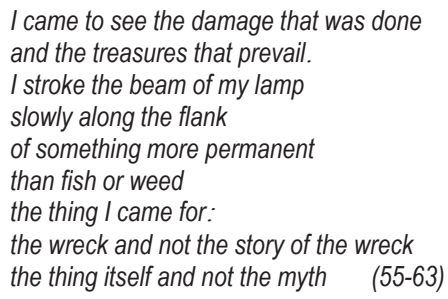

Rich wants to see the damage done to females and to look for 'treasures prevailed'. She is not looking for 'fish or weed', but she wants through her journey to know the truth and to demythologize the story of the wreck, by checking the real wreck herself, seeking hidden history of women. After discovering the female buried treasures, Rich succeeds in incorporating the androgynous ideal, destroying the barriers between the feminine and masculine tradition and transferring the masculine into feminine:

This is the place.

And I am here, the mermaid whose dark hair streams black, the merman in his armored body

We circle silently

about the wreck we dive into the hold.

I am she: I am he

Bryan Aubrey comments on the diver's discovery at the bottoms of the sea when the diver found the drowned face that 'always stare toward the sun among the wrecks' saying:

Set against the rather pessimistic feelings generated by the poem is the striking, twice-mentioned image of the female face carved on the prow of the ship, which appears to have survived intact. The eyes are open and look up to the sun, an image that suggests the tenacity and will to survive of women in general, which seems to be confirmed by the fact that when the diver arrives at the scene he/she indeed discovers the precious metals that remain. It is as if the essence, the gemlike quality of the inner self remains, even in the midst of all the destruction that time and culture have wrought on both men and women. (Milne, 2009, pp. 67-68)

The speaker ends the poem becoming everyone: 'We are, I am, you are'. Everyone becomes a wreck diver because resurrecting the semiotic elements within the symbolic structure of language will help in the creation of a unified unprejudiced language:

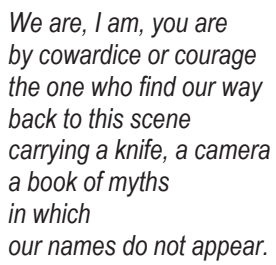

At the end, the poem circles back to the camera and the knife. It ends again with the book of myths: 'in which/ our names do not appear'. There is a glimpse of Rich's anger about the silencing of human experience. The end of the poem makes everyone think about the ways that human history has manipulated language to silence the female voices and to make their personal disasters seem invisible. The end of the poem makes every reader conscious of the negative consequences of burying the female voices and that the way out of this trouble is women's awareness of their situation. As a result, they will work hard to find the means of resurrecting themselves again specially through the means of language. 


\section{Conclusion}

Adrienne Rich's Diving into the Wreck introduces a discourse of restructuring the female identity through the use of an unbiased language. The re-birth of the semiotic elements within the symbolic masculine language can regain to language the feminine elements which lead to the use of a language that is fair to both male and female needs and desires. The persona in Diving dives down to the bottoms of her semiotic subconscious to resurface her female and maternal buried voice and desire which are absented from the scene because of the symbolic masculine language. The persona retells the old-fashioned story of women's oppression and subjugation to patriarchy. This time the story is told through female lens and by female narrator who unmasked the truth of the female story, thus weaponizing women with an appropriate language that restructures and empowers their female identity. The persona at the end of the poem comes into a new realization and awareness of her potentials that prove her ability to find herself.

\section{References}

Abrams, M. H., \& Harpham, G. (2011). A glossary of literary terms: Cengage Learning.

Annas, P. (1982). A Poetry of Survival: Unnaming and Renaming in the Poetry of Audre Lorde, Pat Parker, Sylvia Plath, and Adrienne Rich. Colby Quarterly, 18(1), 3.

Bomarito, J., \& Hunter, J. W. (2005). Feminism in Literature: A Gale Critical Companion (Vol. 6): Thomson Gale.

ERKAN, A. Ü. (2012). An Ecofeminist Approach to Adrienne Rich's Poem "Diving into the Wreck" GEFAD / GUJGEF, (32)(2), 239-249.

Farwell, M. R. (1977). Adrienne Rich and an organic feminist criticism. College English, 191-203.

Forbes, D., \& Forbes, D. (2009). Sincerity's Shadow: Self-consciousness in British romantic and mid-twentieth-century American poetry: Harvard University Press.

Gelpi, B. C., \& Gelpi, A. (1993). Adrienne Rich's poetry and prose: poems, prose, reviews, and criticism: WW Norton.

Gilbert, R. (1997). Framing water: historical knowledge in Elizabeth Bishop and Adrienne Rich. Twentieth Century Literature, 144-161.

Gillis, S., Howie, G., \& Munford, R. (2007). Third wave feminism: A critical exploration: Palgrave Macmillan.

Hay, C. Diving into the Wreck: A Deconstruction of Myth and Identity. from http:// www.chethay.com/398site/wreck.pdf.

Keith, M. D. (2012). Cantatas of the Wild: Memoir, Mysticism, and Modern Feminist Poetry. . In University of California (Ed.). Berkeley.

Kristeva, J. (1984). Revolution in poetic language: Columbia University Press.

McAfee, N. (2004). Julia kristeva: Psychology Press.

Milne, I. M. (2009). Poetry for students. presenting analysis, context and criticism on commonly studied poetry. (Vol. 29). Detroit, Mich.: Gale.

Moi, T. (1986). The Kristeva Reader: Columbia University Press New York.

Ostriker, A. (1982). The thieves of language: Women poets and revisionist mythmaking. Signs: Journal of Women in Culture and Society, 68-90.

Petrović, L. (1997). Gender and Difference in the Poetry of Adrienne Rich. FACTA UNIVERSITATIS-Linguistics and Literature(I-04), 249266.

Rich, A. (1972). When we dead awaken: Writing as re-vision. College English, 18-30.

Roberts, N. (2008). A companion to twentieth-century poetry: John Wiley \& Sons.

Soules, K. (2011, 31 March-2 April). Revitalization of Female History: An Analysis of Adrienne Rich's Diving into the Wreck and The Dream of a Common Language. Paper presented at the The National Conference on Undergraduate Research. , New York. 